\title{
Meeting quality
}

\section{H. Emons}

Published online: 6 March 2013

(c) Springer-Verlag Berlin Heidelberg 2013

Many scientific meetings are taking place all over the world each year. A number of them include presentations about the quality of measurements and its assurance, some even have special sessions related to those aspects, but very few conferences or symposia are fully dedicated to this topic. The International Symposium BERM-13 held in Vienna (Austria) in 2012 was one such meeting. The 13th edition of this conference series was basically a meeting on quality - and what about the quality of the meeting?

Quality assessment is a check on fitness-for-purpose. As conference participants may have very different objectives for attending, the following will represent a personal view on BERM-13. Moreover the evaluation is clearly biased by the personally accumulated knowledge and opinions on former BERM symposia and other conferences, by the selection of attended sessions during the 2012 event and last but not least by the personal involvement in the program preparation.

A quick look on the scientific program for BERM-13 reveals a very interesting trend for this symposium series, namely the increase in the number of different measurement areas which are covered. The name BERM (Biological and Environmental Reference Materials) has nowadays only a historical meaning, as the Vienna meeting expanded even into reference materials for radionuclides and nuclear applications outside environmental monitoring. Topics from food safety and nutrition, laboratory medicine and healthcare, pharmaceuticals and nanotechnology were, as in former BERM symposia, again in the portfolio. It was interesting to note that networking within and between metrology, standardization and accreditation bodies now

H. Emons ( $\square)$

Geel, Belgium

e-mail: JRC-IRMM-ACQUAL@ec.europa.eu also seems to be an established part of the lecture program at this conference.

Another interesting feature could be discovered by looking at who actually took the opportunity to attend this meeting focused on quality. BERM-13 attracted a highly diverse range of participants from many countries including the largest number of 'BERM novices' for many years. This was certainly stimulated by the conference host, the International Atomic Energy Agency (IAEA), and fitted well into the conference location, the United Nation's city in Vienna. But it also demonstrated the increased global awareness of the importance of the quality of measurements and reference materials as crucial tools for laboratories.

When reflecting further on specific aspects of BERM13, I would like to highlight the stronger educational component as cross-cutting program attribute. Training messages were presented in many oral and poster contributions both from new and established BERM-series participants. This qualifies the symposium as an important international platform for knowledge transfer on the quality assurance of measurements. Besides the many interesting lectures, I enjoyed the remarkable poster sessions of the symposium. Indeed the quality of most posters was very good, as were the number and intensity of discussions about them. Moreover, the hospitality of IAEA's organizing team around Aleš Fajgelj, who arranged BERM-13 also in the best Viennese summer season, contributed significantly to the success.

In general my evaluation of the quality of a scientific conference takes into account if the meeting offers professional opportunities to:

- present results, concepts and ideas;

- benchmark one's own work;

- learn from presentations, posters and on-site discussions; 
- meet external collaborators and other colleagues;

- expand one's own scientific networks;

- share general experiences;

- encourage personal values such as motivation and 'scientific community feelings'.

Considering these aspects BERM-13 obtained from me a high-quality mark.

In the following the readership of Accreditation and Quality Assurance (ACQUAL) can examine papers based on presentations from BERM-13. The topics published here range from statistical considerations on variations of measurement results to international standardization via the revision of ISO Guide 35, from reference materials (RMs) for the monitoring of radionuclides to RMs for new genetic measurements in molecular microbiology, from quantitative NMR for assessing the purity of organic RMs with high accuracy to attempts for standardizing allergen measurements, etc. We hope that these papers provide some insight into the topics discussed in Vienna for our colleagues who could not attend.

Hendrik Emons

Editor-in-Chief 